\title{
Ammonia Photolysis and the Greenhouse Effect in the Primordial Atmosphere of the Earth
}

\author{
W. R. KUHN AND S. K. ATREYA \\ Department of Atmospheric and Oceanic Science, Space Physics Research Laboratory, \\ The University of Michigan, Ann Arbor, Michigan 48109
}

Received March 28, 1978; revised July 5, 1978

\begin{abstract}
Photochemical calculations indicate that in the prebiotic atmosphere of the Earth ammonia would have been irreversibly converted to $\mathrm{N}_{2}$ in less than 40 years if the ammonia surface mixing ratio were $\leq 10^{-4}$. However, if a continuous outgassing of ammonia were maintained, radiative equilibrium calculations indicate that a surface mixing ratio of ammonia of $10^{-5}$ or greater would provide a sufficient greenhouse effect to keep the surface temperature above freezing. With a $10^{-4}$ mixing ratio of ammonia, 60 to $70 \%$ of the present day solar luminosity would be adequate to maintain surface temperatures above freezing. A lower limit to the time constant for accumulation of an amount of nitrogen equivalent to the present day value is $10 \mathrm{my}$ if the outgassing were such as to provide a continuous surface mixing ratio of ammonia $\geq 10^{-5}$.
\end{abstract}

\section{INTRODUCTION}

The importance of $\mathrm{NH}_{3}$ to the primitive atmosphere, if indeed it was present, is that its photolysis products could be precursors to prebiotic synthesis (Miller and Urey, 1959) and, in addition, by absorption of longwave radiation $\mathrm{NH}_{3}$ could produce a substantial "greenhouse effect" and maintain a surface temperature above freezing when the solar output was less than today (Sagan and Mullen, 1972). In this study we have calculated the $\mathrm{NH}_{3}$ photolysis products produced by solar ultraviolet radiation for several assumed $\mathrm{NH}_{3}$ atmospheric surface concentrations. We have also made radiation calculations and determined the associated surface temperature increase.

One should note that the primary composition of the prebiotic atmosphere has been a subject of much speculation. Some believe the atmosphere consisted primarily of $\mathrm{CO}, \mathrm{CO}_{2}, \mathrm{~N}_{2}$, and $\mathrm{H}_{2}$ (Abelson, 1966) while others consider $\mathrm{NH}_{3}$ and $\mathrm{CH}_{4}$ to be important constituents (Sagan and Mullen, 1972; Lasaga et al., 1971). Sagan (1977) has estimated the equilibrium $\mathrm{NH}_{3}$ mixing ratio to be $3 \times 10^{-5}$ in the prebiotic atmosphere; for comparison, the $\mathrm{NH}_{3}$ saturation vapor pressure is 10 bar at $300^{\circ} \mathrm{K}$. For this study we assumed a range of $\mathrm{NH}_{3}$ surface mixing ratios from $10^{-4}$ to $10^{-8}$

The background gas is considered inert, i.e., it does not interact with $\mathrm{NH}_{3}$ photochemical products and is not radiatively active. As we show later this gas may have been primarily nitrogen. If $\mathrm{CH}_{4}$ were present its photolysis would have occurred higher in the atmosphere as discussed in the following section. We assume a surface pressure of $780 \mathrm{mbar}$, that of the present day with $\mathrm{O}_{2}$ excluded. If $\mathrm{N}_{2}$ is the primary photodecomposition product of $\mathrm{NH}_{3}$ then this value is reasonable.

The surface temperature calculations are 
based on the assumption that with very little or no water vapor there will be no clouds and thus no latent heat release. One might then expect the tropospheric lapse rate to be nearer its dry adiabatic value which depends on the specific heat capacity. The heat capacity for most gases of planetary interest is about $10^{7} \mathrm{ergs}^{-1}{ }^{\circ} \mathrm{K}^{-1}$ making the adiabatic lapse rate 8 to $10^{\circ} \mathrm{K}$ $\mathrm{km}^{-1}$ (see e.g., Morss and Kuhn 1978). We have used the present day value of $9.8^{\circ} \mathrm{K} \mathrm{km}^{-1}$ for calculations of surface temperature. For comparison we do include a calculation with a lapse rate of $6.5^{\circ} \mathrm{K}$ $\mathrm{km}^{-1}$ such as might exist with cloud formation. The actual lapse rate is not crucial to our conclusions.

Estimates for the increase in solar luminosity over geologic time range from 30 to $60 \%$ (Sagan and Mullen, 1972). We have included these variations in our calculations.

\section{PHOTOCHEMISTRY OF AMMONIA}

In this study we assume that there is no coupling between the ammonia and methane photochemistry primarily since the region of photoabsorption of ammonia is spectrally isolated from that of methane. In addition, if $\mathrm{CH}_{4}$ were present its photodissociation would occur higher in the atmosphere than the $\mathrm{NH}_{3}$ photodissociation (see e.g., Atreya and Donahue, 1978; Atreya, Donahue, and Kuhn, 1978) so that the photolysis products would be spatially separated. Also, although the photodissociation of water vapor would reduce the $\mathrm{NH}_{3}$ concentrations by the reaction $\mathrm{NH}_{3}+\mathrm{OH} \rightarrow \mathrm{NH}_{2}+\mathrm{H}_{2} \mathrm{O}$, Walker (1976) has estimated that over the first billion years $[\mathrm{OH}]$ was only about $10^{5}$ $\mathrm{cm}^{-3}$, which is too small to influence our results. We have also not included possible influence of hot hydrogen reactions. It is doubtful that they would have significant effect on our ammonia chemistry since the atmospheric number density in the region of ammonia photolysis exceeds $10^{18} \mathrm{~cm}^{-3}$.
Various aspects of ammonia photochemistry have been discussed by Strobel (1975), Ferris and Nicodem (1972), and Nicodem and Ferris (1973). The chemical scheme and numerical techniques we use for $\mathrm{NH}_{3}$ photochemistry with transport are similar to those presented for an earlier study for the Jovian atmosphere (Atreya et al., 1977). A brief summary of the parameters as they pertain to the primitive earth atmosphere is given below.

The chemical reactions we assumed are shown in Table I and schematically represented in Fig. 1. Photodissociation of $\mathrm{NH}_{3}$ takes place between 1600 and $2300 \AA$. The recycling of $\mathrm{NH}_{3}$ results largely from the three-body recombination reaction, $\mathrm{R} 2$, of $\mathrm{H}$ with $\mathrm{NH}_{2}$ produced in the ground state in reaction $R 1$. Only a small fraction of $\mathrm{NH}_{3}$ is recycled in this manner, and an even smaller fraction by reaction $R 8$. The net result is the eventual conversion of $\mathrm{NH}_{3}$ to $\mathrm{N}_{2}$ after a series of reactions, R3 through $\mathrm{R} 9$, involving intermediate products such as $\mathrm{N}_{2} \mathrm{H}_{4}$ and $\mathrm{N}_{2} \mathrm{H}_{3}$. From an earlier study by Morss and Kuhn (1978), temperatures in the relevant altitude range of approximately $40 \mathrm{~km}$ above the surface were probably comparable to what we observe today and these temperatures are sufficiently high so as to permit $\mathrm{N}_{2} \mathrm{H}_{4}$ to remain in the gaseous phase. This then allows a direct photodissociation of $\mathrm{N}_{2} \mathrm{H}_{4}$ and all subsequent reactions follow. Calculations were carried out assuming $\mathrm{NH}_{3}$ surface mixing ratios by volume of $10^{-4}$, $10^{-5}, 10^{-6}$, and $10^{-8}$. A mixing ratio of $3 \times 10^{-5}$ corresponds approximately to an equilibrium abundance (Sagan, 1977).

We have included eddy transport in the model although the eddy diffusion coefficient is uncertain, e.g., the dynamics and latent heat release are unknown. We have somewhat arbitrarily assumed the eddy diffusion coefficient to be a constant $10^{5} \mathrm{~cm}^{2} \mathrm{sec}^{-1}$ in agreement with presentday tropospheric models. Calculations were also made with a coefficient one-half this 
TABLE I

Relevant Chemical Reactions and Associated Rate Constants

\begin{tabular}{|c|c|c|c|}
\hline $\begin{array}{l}\text { Reaction } \\
\text { number }\end{array}$ & Reaction & Rate constanta & Reference \\
\hline $\mathbf{R} 1$ & $\mathrm{NH}_{3}+h \nu \rightarrow \mathrm{NH}_{2}(\mathrm{X})+\mathbf{H}$ & $J\left(\mathrm{NH}_{3}\right)$ & $\begin{array}{l}\text { Ackerman (1971), Thompson et al. } \\
\text { (1963), Watanabe (1954) }\end{array}$ \\
\hline $\mathbf{R 2}$ & $\mathrm{NH}_{2}(\mathrm{X})+\mathrm{H} \stackrel{+M}{\rightarrow} \mathrm{NH}_{3}$ & $k_{2}=6 \times 10^{-20}[\mathrm{M}] /\left(1+3 \times 10^{-20}[\mathrm{M}]\right)$ & Gorden et al. (1971) \\
\hline $\mathbf{R 3}$ & $\mathrm{NH}_{2}(\mathrm{X})+\mathrm{NH}_{2}(\mathrm{X}) \stackrel{+M}{\rightarrow} \mathrm{N}_{2} \mathrm{H}_{4}$ & $k_{3}=1 \times 10^{-10}$ & Gorden et al. (1971) \\
\hline $\mathrm{R} 4$ & $\mathrm{~N}_{2} \mathrm{H}_{4}+\mathrm{H} \rightarrow \mathrm{N}_{2} \mathrm{H}_{3}+\mathrm{H}_{2}$ & $k_{4}=9.87 \times 10^{-12} \exp (-1198 / T)$ & Stief and Payne (1976) \\
\hline R5 & $\mathrm{N}_{2} \mathrm{H}_{4}+h_{\nu} \rightarrow \mathrm{N}_{2} \mathrm{H}_{3}+\mathrm{H}$ & $J\left(\mathrm{~N}_{2} \mathrm{H}_{4}\right)$ & $\begin{array}{l}\text { Ackerman (1971), Schürgers and } \\
\text { Welge (1968), Schurath and } \\
\text { SchindIer }(1970)\end{array}$ \\
\hline $\mathbf{R 6}$ & $\mathrm{N}_{2} \mathrm{H}_{3}+\mathrm{H} \rightarrow 2 \mathrm{NH}_{2}$ & $k_{6}=2.7 \times 10^{-12}$ & Gehring et al. (1969) \\
\hline R7 & $\mathbf{H}+\mathbf{H}+\mathbf{M} \rightarrow \mathbf{H}_{2}+\mathbf{M}$ & $k_{7}=8 \times 10^{-3 a}(300 / T)^{0.6}$ & Ham et al. (1970) \\
\hline R8 & $\mathrm{N}_{2} \mathrm{H}_{3}+\mathrm{N}_{2} \mathrm{H}_{3} \rightarrow 2 \mathrm{NH}_{3}+\mathrm{N}_{2}$ & $k_{8} \ll k_{9}$ & Stief (1976, personal communication) \\
\hline R9 & $\begin{aligned} \mathrm{N}_{2} \mathrm{H}_{3}+\mathrm{N}_{2} \mathrm{H}_{3} & \rightarrow \mathrm{N}_{2} \mathrm{H}_{4}+\mathrm{N}_{2} \mathrm{H}_{2} \\
& \rightarrow \mathrm{N}_{2} \mathrm{H}_{4}+\mathrm{N}_{2}+\mathrm{H}_{2}\end{aligned}$ & $k_{9}=6 \times 10^{-11}$ & Stief (1976, personal communication) \\
\hline
\end{tabular}

a Rate constants $k$ 's (in $\left.\mathrm{cm}^{3} \mathrm{sec}^{-1}\right)$ for two-body reactions and $\left(\mathrm{cm}^{6} \mathrm{sec}^{-1}\right)$ for three body reactions. Photodissociation rates $J\left(\mathrm{NH}_{3}\right)$ and $J\left(\mathrm{~N}_{2} \mathrm{H}_{4}\right)$ (in $\left.\mathrm{sec}^{-1}\right)$.

value to determine the influence of eddy transport on the photochemical constituents.

Since some of the rate constants in Table I are temperature dependent it was necessary to assume an atmospheric temperature profile. We assumed a lapse rate of $6^{\circ} \mathrm{K} \mathrm{km}^{-1}$ from the surface to $27 \mathrm{~km}$ and an isothermal atmosphere above. The surface temperature was $292^{\circ} \mathrm{K}$. This profile corresponds approximately to the primitive atmosphere temperature profiles of Morss and Kuhn (1978). The calculations were found to be insensitive to the choice of spectral intervals smaller than $10 \AA$ and altitude intervals less than $1 \mathrm{~km}$. Onedimensional coupled continuity and trans-

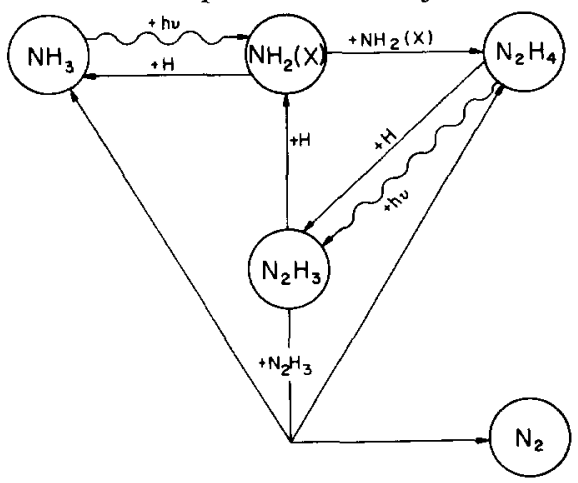

FIG. 1. Schematic representation of the $\mathrm{NH}_{3}$ photochemistry. port equations were then solved for a steady-state case by the Newton-Raphson finite-difference method.

Photodissociation rates of $\mathrm{NH}_{3}$ are shown in Fig. 2. One notes a large variation in these rates with different surface mixing ratios of $\mathrm{NH}_{3}$. As expected, for large values of $\mathrm{NH}_{3}$ mixing ratio, most of the photodissociation occurs near the top, i.e., above $30 \mathrm{~km}$. For $\mathrm{NH}_{3}$ mixing ratios of about $10^{-8}$, the atmosphere is essentially transparent to the ultraviolet radiation between 1600 and $2300 \AA$.

The distributions of $\mathrm{NH}_{3}$ and its products $\mathrm{H}, \mathrm{NH}_{2}, \mathrm{~N}_{2} \mathrm{H}_{3}$, and $\mathrm{N}_{2} \mathrm{H}_{4}$ are shown in Fig. 3. With the exception of $\mathrm{NH}_{3}$, these distributions are all for the case in which $K=10^{5} \mathrm{~cm}^{2} \mathrm{sec}^{-1}$ and a surface mixing ratio of $\mathrm{NH}_{3}$ of $10^{-5}$. For $\mathrm{NH}_{3}$, however, results of a sensitivity study with $\mathrm{NH}_{3}$ volume mixing ratios of $10^{-4}, 10^{-6}$, and $10^{-8}$, and one with $10^{-5}$ but $K=5 \times 10^{4}$ $\mathrm{cm}^{2} \mathrm{sec}^{-1}$ are also shown. In all these cases photolysis leads to a rapid conversion of $\mathrm{NH}_{3}$ to $\mathrm{N}_{2}$; the concentration of other nitrogen bearing compounds is small. Practically no ultraviolet radiation in the 1600 to $2300 \AA$ range penetrates to the surface when the $\mathrm{NH}_{3}$ surface mixing ratio is greater than $10^{-6}$. One also notes in 


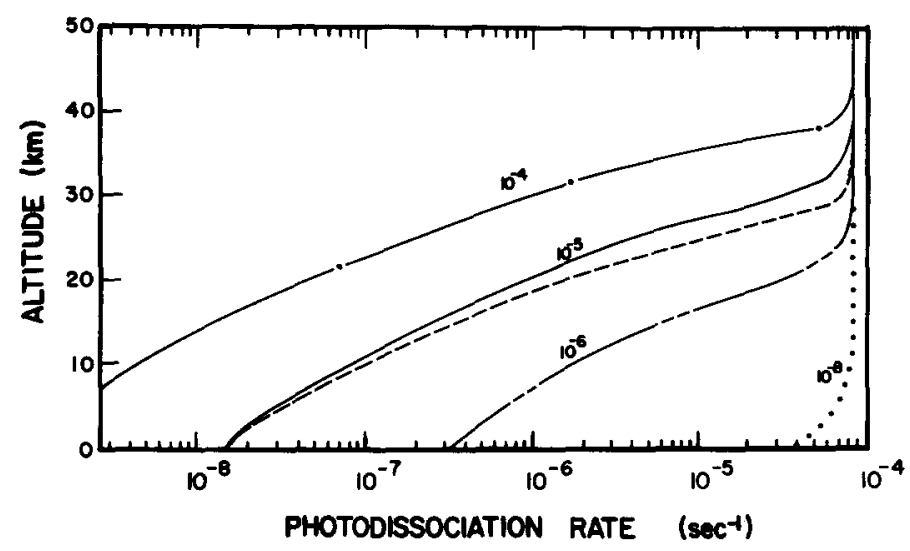

FIG. 2. Photodissociation rates of $\mathrm{NH}_{3}$ for $\mathrm{NH}_{3}$ surface mixing ratios of $10^{-4}, 10^{-5}, 10^{-6}$, and $10^{-8}$ with an eddy diffusion coefficient, $K=10^{5} \mathrm{~cm}^{2} \mathrm{sec}^{-1}$. The broken line curve is for an $\mathrm{NH}_{3}$ surface mixing ratio of $10^{-5}$ but with $K=5 \times 10^{4} \mathrm{~cm}^{2} \mathrm{sec}^{-1}$.

Fig. 2 that photolysis to greater depths results when $K=5 \times 10^{4} \mathrm{~cm}^{2} \mathrm{sec}^{-1}$ than in the case when $K=10^{5} \mathrm{~cm}^{2} \mathrm{sec}^{-1}$. This occurs because in the higher eddy mixing case ammonia remains mixed to greater altitudes thus causing most of the absorption and hence photolysis to take place in the upper altitude range. If the eddy diffusion coefficient were $10^{2} \mathrm{~cm}^{2} \mathrm{sec}^{-1}$, then photolysis would occur at the surface and the atmospheric $\mathrm{NH}_{3}$ concentrations would be much smaller than shown. Furthermore, it should be noted that the greenhouse effect discussed in the following section is independent of the choice of eddy diffusion coefficient.

\section{AMMONIA GREENHOUSE EFFECT}

The possible importance of $\mathrm{NH}_{3}$ to the greenhouse effect on the primitive Earth has been suggested by Sagan and Mullen (1972) and Sagan (1977). They divided the spectrum into transparent regions corresponding to emission from the Earth's surface and opaque regions corresponding to the absorption bands of the atmospheric

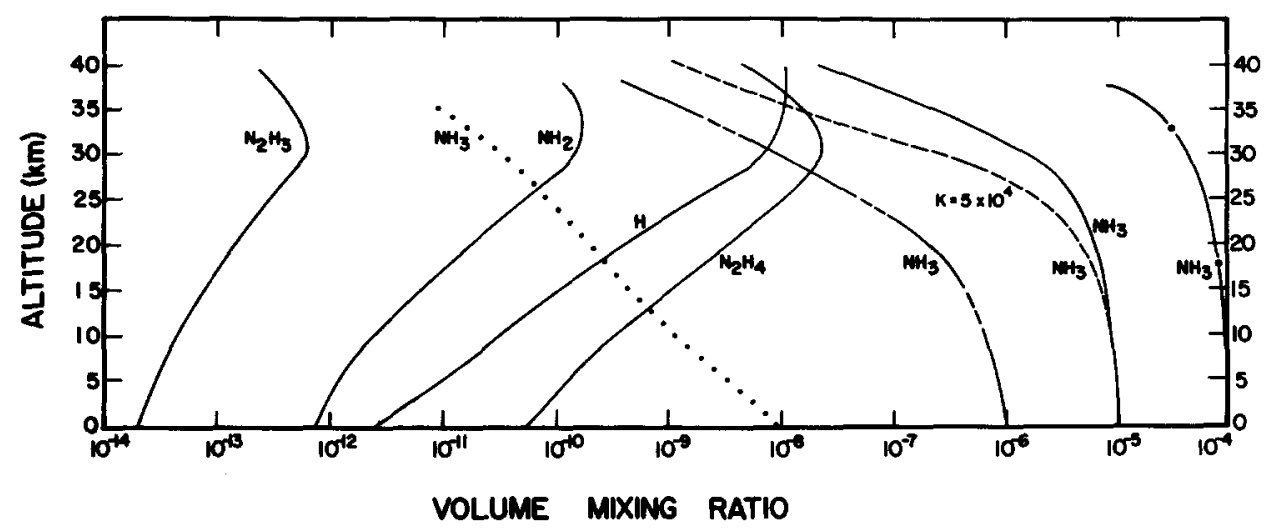

Fig. 3. Volume mixing ratios of $\mathrm{NH}_{3}, \mathrm{H}, \mathrm{NH}_{2}, \mathrm{~N}_{2} \mathrm{H}_{4}$, and $\mathrm{N}_{2} \mathrm{H}_{3}$ with an $\mathrm{NH}_{3}$ surface mixing ratio of $10^{-5}$ and an eddy diffusion coefficient $K=10^{5} \mathrm{~cm}^{2} \mathrm{sec}^{-1}$ are shown by solid lines. also shown are $\mathrm{NH}_{3}$ mixing ratio profiles for $K=10^{5} \mathrm{~cm}^{2} \sec ^{-1}$ and with $\mathrm{NH}_{3}$ surface ratios of $10^{-4}$, $10^{-6}$, and $10^{-8}$. The broken line curve represents the case for $K=5 \times 10^{4} \mathrm{~cm}^{2} \mathrm{sec}^{-1}$ and an $\mathrm{NH}_{3}$ surface mixing ratio of $10^{-5}$. 


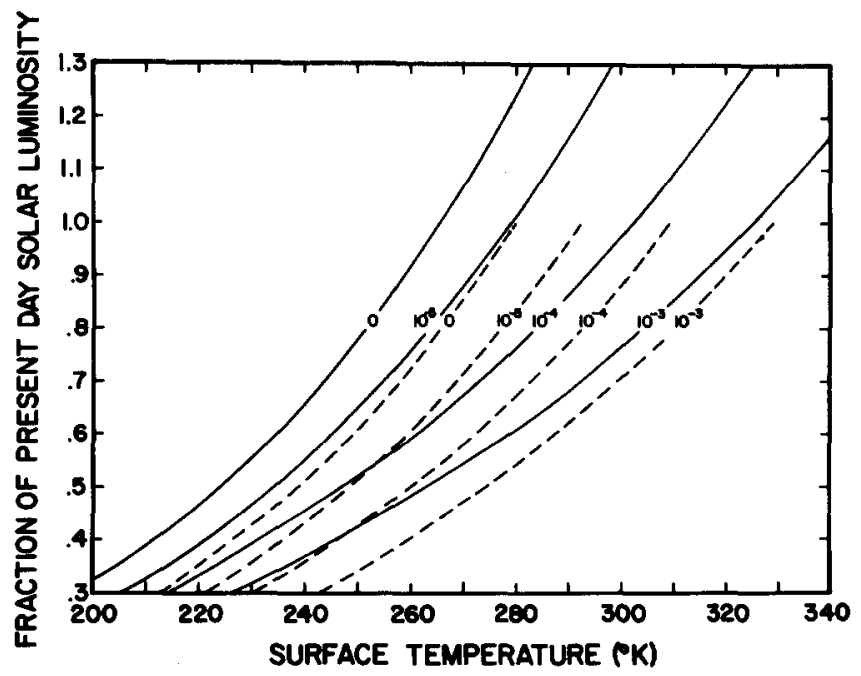

FIG. 4. Mean surface temperatures of the primitive earth for different solar luminosities. Numbers on the curves are the mixing ratios of ammonia. Solid curves are for a lapse rate of $-9.8^{\circ} \mathrm{K} / \mathrm{km}$ with no $\mathrm{H}_{2} \mathrm{O}$ present and the dashed curves correspond to a $-6.5^{\circ} \mathrm{K} / \mathrm{km}$ lapse rate and includes the present day $\mathrm{H}_{2} \mathrm{O}$ amount.

gases. In the latter case the outward radiation was assumed to originate from the isothermal stratosphere. They then equated the outward thermal radiation to the absorbed solar radiation and determined a mean surface temperature. If the solar luminosity were tens of percent less than today, and the atmospheric composition were the same, then the surface temperature would have been below the freezing point of water, making organic synthesis almost impossible. Sagan (1972) estimated that for an equilibrium abundance of $\mathrm{NH}_{3}$ with volumetric mixing ratio of $3 \times 10^{-5}$, the surface temperature would have been about $320^{\circ} \mathrm{K}$ for present day solar flux, i.e., a greenhouse effect of about $32^{\circ} \mathrm{K}$.

We have calculated from a radiative transfer model (for details see Kuhn et al., 1978) surface temperatures for various $\mathrm{NH}_{3}$ concentrations and percentages of solar luminosity (Fig. 4). Since the $\mathrm{H}_{2} \mathrm{O}$ amount is so uncertain, we have made two separate calculations; one in which the water vapor is absent from the atmosphere and the other utilizing the present day midlatitude water vapor distribution. To allow for a different albedo than observed today (30\%), we have extended the calculations to a solar output of 1.3 times the present value, which corresponds to a $10 \%$ albedo for the Earth-atmosphere system. For example, if for the present-day sclar flux the albedo were only $20 \%$ then the correct value for the ordinate on Fig. 3 would be 1.14. The $\mathrm{CO}_{2}$ mixing ratio is $4.56 \times 10^{-4}$. No ozone was included in the model. The $\mathrm{NH}_{3}$ mixing ratio varied from $10^{-3}$ to $10^{-5}$. Results indicated the lapse rate was superadiabatic for all $\mathrm{NH}_{3}$ mixing ratios. Thus a convective adjustment was applied, i.e., the lapse rate was adjusted to be $6.5^{\circ} \mathrm{K} \mathrm{km}^{-1}$ for the present day water vapor distribution and equal to the dry adiabatic value of $9.8^{\circ} \mathrm{K} \mathrm{km}^{-1}$ when no water vapor was included.

If the atmosphere contained no ammonia then the surface temperature would be between 265 and $280^{\circ} \mathrm{K}$ depending on the $\mathrm{H}_{2} \mathrm{O}$ amount. With the present day $\mathrm{H}_{2} \mathrm{O}$ abundance this is still some $8^{\circ} \mathrm{K}$ below the mean temperature today because the primitive atmosphere we assumed contains no oxygen and thus the total pressure is 
only 780 mbar. The thermal radiation to space will therefore be larger, leading to a lowered surface temperature. For an $\mathrm{NH}_{3}$ mixing ratio of $10^{-5}$ the greenhouse effect would increase the temperature by some 12 to $15^{\circ} \mathrm{K}$. If the lapse rate were adiabatic

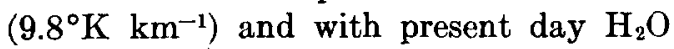
amounts the surface temperature increase would be close to Sagan's (1977) estimate.

\section{CONCLUSIONS}

We have shown that even with significant lowering of the solar luminosity, surface temperatures in the primitive atmosphere could be maintained above freezing if the $\mathrm{NH}_{3}$ concentration were $10^{-5}$ or larger; freezing would occur if the luminosity dropped by 10 to $25 \%$ depending on the amount of $\mathrm{H}_{2} \mathrm{O}$ present. If the concentration were $10^{-4}$, then a solar output of only 60 to $70 \%$ the present value would be adequate to maintain the temperature above freezing. One must remember, however, that this greenhouse effect could only be maintained so long as there was a continuous source of $\mathrm{NH}_{3}$ to the atmosphere, presumably by outgassing. Abelson (1966) first suggested that the lifetime of $\mathrm{NH}_{3}$ would be short because of its photochemical dissociation. We find that if the initial $\mathrm{NH}_{3}$ mixing ratio was $10^{-4}$ then in only 40 years the $\mathrm{NH}_{3}$ would have been destroyed through photolysis. If the mixing ratio were $10^{-5}$, then the lifetime was less than 10 years. Thus the $\mathrm{NH}_{3}$ greenhouse effect would have been restricted to the time over which outgassing occurred.

A significant amount of $\mathrm{N}_{2}$ could have been produced by $\mathrm{NH}_{3}$ photolysis. The minimum time for the atmosphere to accumulate an amount of $\mathrm{N}_{2}$ equal to that of the present day was 10 my if outgassing could have maintained an $\mathrm{NH}_{3}$ surface mixing ratio of $10^{-5}$. The actual time may have been appreciably longer, however, since the photolysis products of $\mathrm{NH}_{3}$ could also have reacted with other constituents in the primitive atmosphere such as the hydroxyl radical.

\section{ACKNOWLEDGMENTS}

We thank D. Kraemer for numerical assistance. This work was supported by NASA Grants NSG 7308 and NSG 7404.

\section{REFERENCES}

Abelson, P. H. (1966). Chemical events on the primitive Earth. Proc. Nat. Acad. Sci. USA 55, 1365-1372.

ACKerman, M. (1971). Ultraviolet solar radiation related to mesospheric processes. In Mesospheric Models and Related Expts (G. Fiocco, Ed.). Reidel, Dordrecht.

Atreya, S. K., and Donahue, T. M. (1976). Model ionospheres of Jupiter. In Jupiter ( $T$. Gehrels, Ed.). Univ. Arizona Press, Tucson.

Atreya, S. K., Donahue, T. M., and Kuhn, W. R. (1977). The distribution of ammonia and its photochemical products on Jupiter. Icarus 31, 348-355.

Ferris, J. P., And Nicodem, D. E. (1972) Ammonia photolysis and the role of ammonia in the chemical evolution. Nature 238, 268-269.

Gehring, M., Hoyermann, G., Wagner, H. G., AND Wolfrum, J. (1969). Reaction of atomic hydrogen with hydrazine. Ber. Bunsenges. Phys. Chem. 73, 956.

Gordon, S., Mulac, W., and Nangra, P. (1971). Pulse radiolysis of ammonia gas. II. Rate of disappearance of the $\mathrm{NH}_{2}\left(X^{2} B_{1}\right)$ radical. $J$. Phys. Chem. 75, 2087-2093.

Ham, D. I., Trainor, D. W., and Kaumman, F. (1970). Gas phase kinetics of $\mathrm{H}+\mathrm{H}+\mathrm{H}_{2}$ $\rightarrow 2 H_{2}$. J. Chem. Phys. 53, 4395-4396.

Kuhn, W. R., Krakmer, D., Cicerone, R., and LIU, S. (1978). Radiative equilibrium temperatures in the stratosphere and mesosphere-A comparison for the stellar occultation and BUV ozone data. Geophys. Res. Lett. 5, 365-368.

Lasaga, A. C., Holland, H. D., and Dwyer, M. J. (1971). Primordial oil slick. Science 174, 53-55.

Miller, S. L., and Urey, H. C. (1959). Organic compound synthesis on the primitive earth. Science 130, 245-251.

Morss, D., ANd Kunn W. R. (1978). Paleoatmospheric temperature structure. Icarus 33, 40-49

Nicodem, D. E., and Ferris J. P. (1973) Ammonia photolysis on Jupiter. Icarus 19, 495-498.

SaGAN, C., ANd Mulleen, G. (1972). Earth and Mars: Evolution of atmospheres and surface temperatures. Science 177, 52-55.

SAGAN, C. (1977). Reducing greenhouses and the temperature history of Earth and Mars. Nature 269, 224-226. 
Schurath, U., and Schindler, R. M. (1970). The photolysis of hydrazine at $2060 \AA$ in the presence of ethylene. J. Phys. Chem. 74, 3188-3194.

Schürgers, M., and Welge, K. H. (1968). Absorptionkoeffizinet von $\mathrm{H}_{2} \mathrm{O}_{2}$ zwischen 1200 und 2000 A. Z. Naturforsch. $A$ 23, 1508-1510.

Stief, L. J., ANd Payne, W. A. (1976). Absolute rate parameter for the reaction of atomic hydrogen with hydrazine. $J$. Chem. Phys. 64, 4892-4897.

Strobel, D. F. (1975). Aeronomy of the major planets. Photochemistry of ammonia and hydrocarbons. Rev. Geophys. Space Phys. 13, 372-382.

Thompson, B. A., Harteck, P., and Reeves, R.
R., JR. (1963). Ultraviolet absorption coefficients of $\mathrm{CO}_{2}, \mathrm{CO}, \mathrm{O}_{2}, \mathrm{H}_{2} \mathrm{O}, \mathrm{N}_{2} \mathrm{O}, \mathrm{NH}_{3}, \mathrm{NO}, \mathrm{SO}_{2}$ and $\mathrm{CH}_{4}$ between 1850 and 4000 А. J. Geophys. Res. $68,6431-6436$.

WALkER, J. C. G. (1976). Implications for atmospheric evolution of the inhomogeneous accretion model of the origin of the Earth. In The Early History of the Earth (B. F. Windley, Ed.), pp. 537-546. Wiley, New York.

Watanabe, K. (1954). Photoionization and total absorption cross section of gases. I. Ionization potential of several molecules. Cross sections of $\mathrm{NH}_{3}$ and NO. J. Chem. Phys. 22, 1564-1570. 